\title{
Choques nos Preços dos Ativos e a Dinâmica das Decisões de Política Macroeconômica: uma Análise da Resposta Fiscal e Monetária a uma Bolha Habitacional
}

\section{Shocks in Asset Prices and the Dynamics of Macroeconomic Policy Decisions: an Analysis of the Fiscal and Monetary Response to a Housing Bubble}

Cássio Nóbrega Besarria*

\begin{abstract}
Resumo: O objetivo deste artigo é investigar os indícios de bolhas racionais nos preços das habitações e analisar os efeitos dos choques nos preços desses ativos nos instrumentos de política monetária e fiscal. A discussão sobre bolhas se limita à análise dos preços das habitações e seus dividendos por meio de testes de cointegração linear e com quebra estrutural. Os resultados sugerem que há indícios de bolhas no mercado habitacional brasileiro. A discussão subsequente avalia os efeitos desse choque no comportamento das séries da inflação, PIB real, consumo das famílias, taxa Selic, receita e despesa governamental, mercado de trabalho e financiamento habitacional, por meio do modelo de vetores autorregressivos. Em suma, observa-se que a bolha estimula a atividade fiscal em um comportamento pró-cíclico. Por outro lado, se verifica que a política monetária, buscando estabilizar a inflação e o produto, tem levado em consideração os possíveis efeitos desestabilizadores causados pela bolha.
\end{abstract}

Palavras-chave: Bolhas racionais. Política monetária. Política fiscal. SVAR.

\begin{abstract}
The objective of this article is subdivided in the investigation of rational bubbles evidences in the housing prices and in the analysis of shock effects in these asset prices, in monetary and fiscal policy instruments. The discussion about bubbles was limited to the analysis between housing prices and their dividends through linear cointegration tests with structural break. The results suggested that there are evidences of bubbles in the Brazilian housing market. The subsequent discussion evaluated the effects of this shock on the behavior of inflation series, real GDP, household consumption, Selic rate, revenue and government expenditure, labor market and housing finance, through the SVAR model. In short, it was observed that the bubble stimulated fiscal activity in a pro-cyclical behavior. On the other hand, it was found that the monetary policy, aiming to stabilize the inflation and the product, has taken into account the possible destabilizing effects caused by the bubble.
\end{abstract}

Keywords: Rational bubbles. Monetary policy. Fiscal policy. SVAR.

JEL Classification: C11; E52; E62; G12.

Doutor pelo Programa de Pós-Graduação em Economia da Universidade Federal de Pernambuco (PIMES/UFPE). Professor do curso de Economia da Universidade Federal da Paraíba (UFPB). E-mail: cassiodanobrega@yahoo.com.br 


\section{1 lntrodução}

O cenário econômico recente mostrou que o motivo de preocupação com o aumento nos preços das habitações está ligado a uma série de acontecimentos que podem ser associados ao crescimento excessivo dos preços desses ativos. Observando a experiência do Japão no final da década de 1980, e dos Estados Unidos na crise subprime, é possível concluir que os preços dos ativos (habitações e ações) desempenharam um papel importante nas flutuações econômicas nesse período. Essa experiência indica que a instabilidade macroeconômica nesses países esteve fortemente relacionada a grandes flutuações nos preços dos ativos e levanta a questão sobre a forma adequada de tratar os preços dos ativos (habitações) na formulação de políticas macroeconômicas.

Recentemente, tem se levantado a possibilidade de existência de bolhas na economia brasileira, principalmente devido à combinação de acumulação de crédito e aumentos nos preços das habitações. Essa discussão teve início em 2009, quando, com o objetivo de reduzir o déficit habitacional e os efeitos da crise subprime, foi implantado na economia brasileira o programa habitacional conhecido como Minha Casa, Minha Vida.

Esse programa, associado a um conjunto de fatores que, descritos por Mishkin (2007), chamou a atenção, tais como crédito subsidiado para a compra de imóvel residencial, oferta de habitação fixa no curto prazo e elevado custo de produção, tem promovido o crescimento excessivo nos preços habitacionais e levantado a possibilidade de existência de uma bolha no setor habitacional brasileiro.

Essa discussão ganhou força quando autoridades como o ex-presidente do Banco Central do Brasil Henrique Meirelles (2013) e o ganhador do prêmio Nobel de Economia Robert Shiller (2013) passaram a alertar quanto à presença de bolha nos preços das habitações brasileiras, dando ênfase para o crescimento excessivo dos preços desses ativos, principalmente nas cidades de São Paulo e Rio de Janeiro.

Baseando-se nessas possibilidades, este artigo procura preencher as seguintes lacunas: a) há indícios de bolhas na economia brasileira?; b) se sim, como a política monetária e fiscal tem reagido aos choques nos preços das habitações? Para responder ao primeiro questionamento, são utilizados os modelos de bolhas racionais, que tratam a existência de bolhas a partir da relação entre os preços das habitações e os seus dividendos (aluguéis).

No atual estágio de desenvolvimento deste artigo é possível verificar que não há uma quantidade expressiva de estudos voltados para a identificação de bolhas nos preços das habitações, assim como uma análise dos efeitos macroeconômicos do crescimento excessivo dos preços desse ativo na economia brasileira. Sobre essa temática foram encontrados os estudos propostos por Mendonça, Medrano 
e Sachsida (2011), Mendonça e Sachsida (2012), Besarria, Paes e Silva (2014) e Silva, Besarria e Carvalho (2014).

Quanto ao processo de identificação de bolhas, essa é uma temática ainda controversa na literatura econômica, não havendo consenso entre os pesquisadores. No entanto, a escolha pelo modelo de bolhas racionais se deu pelo fato que grande parte da literatura internacional, tal como os estudos de Campbell e Shiller (1988), Diba e Grossman (1988), Froot e Obstfeld (1991), Evans (1991), Timmermann (1995), Wu (1997), Crowder e Wohar (1998), Bohl (2003), Nasseh e Strauss (2004), Cunado, Gil-Alana e Gracia (2005), Mokhtar, Nassir e Hassan (2006) e Chang, Chiu e Nieh (2007), entre outros, passou a investigar a presença de bolhas racionais nos mercados de ativos por meio do método de cointegração.

A ocorrência de bolhas racionais significa que não há relação de longo prazo entre os preços dos ativos e seus dividendos, sendo que os estudos empíricos, em sua maioria, têm empregado técnicas de cointegração nessa investigação. Entre as diversas formulações que procuram captar a relação entre os preços dos ativos e seus valores fundamentais, este artigo se limita aos processos cointegrados lineares e com quebra estrutural, diferentemente das discussões propostas por Besarria, Paes e Silva (2014) e Mendonça e Sachsida (2012), em que os primeiros realizam sua análise por meio dos testes de cointegração lineares e não lineares e os segundos tratam o processo de identificação de bolhas por meio dos princípios da Teoria Austríaca do Ciclo Econômico (Tace).

Em seguida, as bolhas são tratadas como um choque exógeno e expansionista nos preços das habitações brasileiras, como nas pesquisas de Filardo (2001) e Besarria, Paes e Silva (2014), sendo analisados os efeitos fiscais e monetários do choque nos preços das habitações. Este artigo se diferencia da análise proposta por Besarria, Paes e Silva (2014) pelo fato que esses autores analisam apenas os efeitos monetários do choque, sem incluir os efeitos fiscais.

A importância dessa discussão está ligada aos estímulos monetários e fiscais que são criados devido à presença da bolha nos preços das habitações. Em relação aos estímulos monetários, destaca-se o mecanismo de transmissão conhecido na literatura como efeito riqueza sobre o consumo. $\mathrm{O}$ aumento nos preços das habitações ${ }^{1}$ se traduz em ganhos na riqueza imobiliária dos agentes econômicos detentores desse ativo, incrementando o seu consumo. Outra consequência desse choque são as condições de financiamento das famílias: à medida que as habitações se valorizam, essa apreciação flexibiliza as restrições colaterais ou garantias que ligam a capacidade de crédito das famílias com o valor de suas casas. Com isso, quanto maior a sensibilidade das decisões de consumo das famílias, motivada pela flexibi-

1 Muellbauer (1994) destaca que o aumento nos preços das habitações pode ter efeitos ambíguos: efeito positivo (efeito riqueza) e efeito negativo de preços relativos (efeito rendimento e substituição). 
lização das condições de financiamento, mais vulneráveis estarão a mudanças nos ciclos dos preços das habitações.

Por outro lado, o aumento nos preços das habitações desempenha papel importante nos ganhos de arrecadação dos governos municipais. ${ }^{2}$ Dentre os canais fiscais, destacam-se o imposto sobre a propriedade e o imposto de transferência de imóveis, os quais estão diretamente ligados ao valor dos imóveis e ao volume de transações de bens imobiliários. Indiretamente, a arrecadação fiscal é afetada pelos impostos sobre vendas de materiais utilizados em novas construções e renovação das estruturas existentes. Por fim, a expansão da restrição orçamentária governamental pode promover a expansão dos gastos públicos que, caso ocorra, se traduz em efeitos keynesianos tradicionais, tais como expansão da demanda agregada e ampliação da demanda por emprego.

Além desta introdução, a seção 2 descreve o modelo de bolhas racionais, a seção 3 apresenta os procedimentos empíricos e a base de dados, a seção 4 apresenta os resultados obtidos pelos testes de cointegração e os efeitos dos choques sobre os preços das habitações e a seção 5 traz as considerações finais.

\section{Decisões Monetárias e Fiscais Adotadas após a Eclosão da Crise Subprime}

Esta seção tem o propósito de apresentar algumas das decisões de política macroeconômica assumidas devido à bolha nos preços das habitações americanas, também conhecida como crise subprime. Apesar de este artigo tratar dos efeitos do aumento nos preços das habitações sobre os instrumentos de política monetária e fiscal, é importante mostrar a postura adotada pelos gestores de política macroeconômica após a ruptura da bolha habitacional americana.

Grande parte da literatura econômica tem procurado identificar os canais através dos quais a política monetária possa ter contribuído para o surgimento desses desequilíbrios financeiros. Conforme destacam Merrouche e Nier (2010), parte dessa discussão mostra que a política monetária frouxa, ou expansionista, nos Estados Unidos após a recessão de 2001 pode ter promovido uma redução do custo de financiamento, levando à acumulação de alavancagem (ADRIAN; SHIN, 2008) e também pode ter incentivado mais bancos a assumir mais riscos, incluindo riscos de crédito e de liquidez (BORIO; ZHU, 2008), resultando em bolhas no mercado de imóveis e ações.

Nessa mesma linha de argumentação, Taylor (2007) mostra que essas baixas taxas de juros e o fornecimento de grandes quantidades de liquidez ajudou a promover o aumento na demanda por habitação. Como as taxas de juros eram baixas, o custo do financiamento habitacional era muito barato e atraente, especialmente

2 Trata-se do imposto sobre propriedade territorial urbana (IPTU) e do imposto sobre transferências de bens imóveis (ITBI). 
com as taxas de hipotecas variáveis. O preço da habitação passou por um processo de apreciação de 25 anos, sendo o ciclo de alta iniciado na década de 1970 e com reversão a partir de 2006.

O aumento da procura por habitação levou a um aumento na inflação de preço da habitação, que já estava elevado desde meados de 1990. A taxa de inflação da habitação, medida pelo índice de preços Office of Federal Housing Enterprise Oversight (OFHEO), chegou a uma taxa anual de 10\%, no quarto trimestre de 2004, e permaneceu por mais de $10 \%$ nos dois anos subsequentes. Medido pelo índice de habitação Case-Shiller, a inflação ultrapassou $20 \%$ durante parte desse período. Junto com o aumento nos preços das habitações, caiu o número de execução hipotecária subprime, o que gerou uma política de crédito rating mais favorável do que poderia vir a ser sustentada.

Destaca-se que, após a ruptura da bolha, a taxa de juros passou a ter papel de destaque devido ao aumento do risco de deflação. Esse componente passa a ser considerado um risco devido ao fato de a deflação de preços intensificar a desaceleração da atividade econômica. ${ }^{3} \mathrm{O}$ fato de a inflação ter ficado negativa em 2009 fez com que o Banco Central americano experimentasse uma situação que foi considerada há algumas décadas como uma mera curiosidade teórica: chegaram a um limite inferior das taxas de juros overnight, apesar de o produto estar abaixo da capacidade desejada.

Como destaca Woodford (2012), a possibilidade teórica de chegar a tal situação se tornou um desafio para o Banco Central do Japão (BOJ) no final de 1990, quando até mesmo uma eventual redução da taxa de juros overnight para zero não foi suficiente para deter a deflação no Japão. Nesses casos, a capacidade de estímulo econômico por meio de cortes nas taxas de juros passou a ser reduzida.

Para o caso dos Estados Unidos, quando os bancos centrais chegaram ao limite inferior de sua taxa de juros (em torno de zero no final de 2008), passaram a utilizar as mudanças no equilíbrio do balanço do Banco Central - sua dimensão global, a composição de seus ativos e a participação de seus passivos como instrumento de política monetária (balance sheet policies) expansionista. Esse tipo de instrumento de política monetária é abordado pela teoria da flexibilização quantitativa e tem o propósito de estimular o aumento das despesas agregadas e, consequentemente, a atividade econômica por meio da expansão da base monetária.

No entanto, o processo de expansão da base monetária que se iniciou em 2008 não afetou de forma imediata a taxa de crescimento do PIB nominal e o nível de preços. Assim, como destacam Blanchard, Dell'Ariccia e Mauro (2010), na medida em que a política monetária, incluindo reduções na taxa de juros e flexibi-

3 Decressin e Laxton (2009) mostram que episódios passados de deflação na sequência de colapsos de bolhas nos preços dos ativos e crises bancárias têm sido associados com o desempenho econômico fraco, como ocorreu no Japão na década de 1990. 
lização quantitativa, atingiu em grande parte os seus limites, a política fiscal passou a ser utilizada como ferramenta anticíclica.

Conforme destacam Blanchard, Dell'Ariccia e Mauro (2010), a crise subprime trouxe a política fiscal para o centro do palco como instrumento de estímulo econômico, e isso se deu por duas razões: primeiro, na medida em que a política monetária, como já descrito, atingiu em grande parte os seus limites, os gestores tinham que adotar alternativas, tais como instrumentos de política fiscal; segundo, das suas fases iniciais era esperado que a recessão fosse de longa duração, de modo que era evidente que o estímulo fiscal teria tempo suficiente para produzir um impacto benéfico.

Dessa forma, os anos 2000 se caracterizaram por apresentar dois períodos distintos de política fiscal para as economias avançadas (Estados Unidos, Alemanha, Japão e Reino Unidos): o primeiro, relativo aos anos que antecederam a crise subprime, em que a condução da política fiscal nessas economias se caracterizou pela estabilidade nos principais indicadores fiscais; e o segundo, a partir de 2006, quando a condução da política fiscal apresentou diferenças marcantes, caracterizando-se pelos desequilíbrios fiscais e pelo aumento das vulnerabilidades externas.

A dívida bruta do governo geral dos Estados Unidos e do Japão atingiu 103\% e $229 \%$ do PIB, respectivamente, em 2011, ante 67\% e 186\%, em 2006 (período que antecedeu a crise), respectivamente. A elevação desse indicador nas economias avançadas e na União Europeia decorreu do baixo crescimento do PIB a partir de 2008 e, sobretudo, devido ao aumento das medidas de apoio ao setor financeiro, envolvendo a transferência de ativos/passivos para o balanço do setor público.

Outro indicador que representa o comportamento do governo central na crise subprime é o balanço estrutural, representado pelo Gráfico 1. De acordo com Paes (2012), o balanço estrutural mede como o balanço fiscal real seria se o produto estivesse no seu nível potencial. A mudança no balanço estrutural de um período para outro é considerada como uma medida do componente discricionário da política fiscal, ou seja, aquele que resulta de uma decisão de governo. 
Gráfico 1 - Balanço estrutural do governo geral (\% PIB)

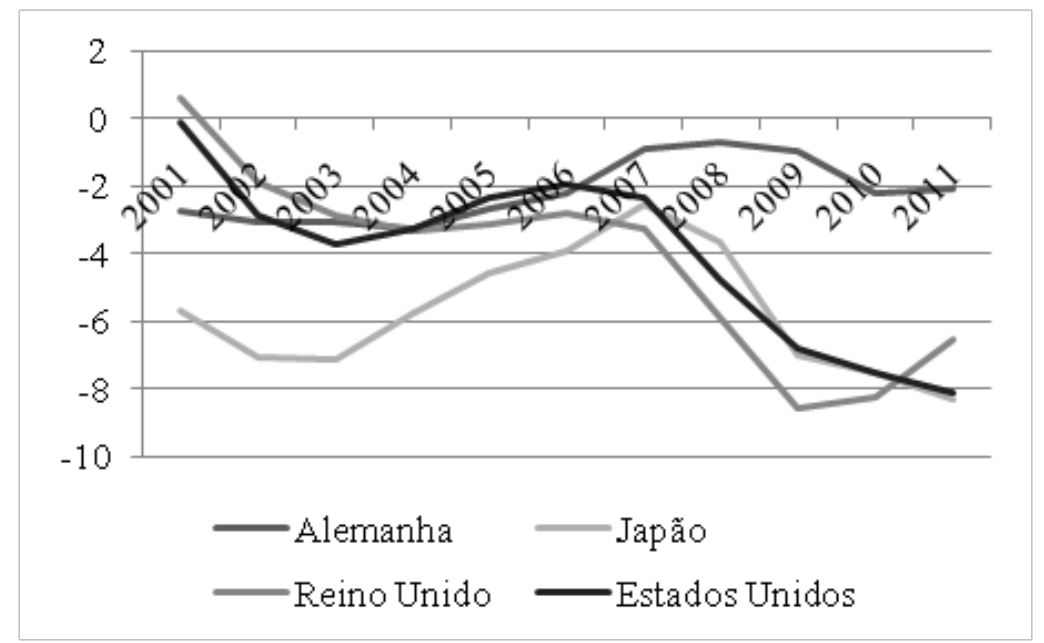

Fonte: Elaboração própria a partir de International Monetary Fund (2012).

Analisando o Gráfico 1, é possível perceber que, com exceção da Alemanha, países como Japão, Reino Unido e Estados Unidos apresentaram uma política fiscal expansionista desde 2007, indicando políticas fiscais anticíclicas de caráter discricionário, sendo que o déficit estrutural no Reino Unido, Estados Unidos e Japão indica que o produto efetivo está abaixo do produto potencial, implicando redução das receitas e aumento de subsídios de desemprego. Assim, a partir do Gráfico 1, conclui-se que os países avançados ampliaram seus déficits fiscais estruturais.

\section{Procedimentos Metodológicos}

Os procedimentos metodológicos adotados neste artigo se subdividem em duas etapas, sendo que inicialmente serão discutidos os testes estatísticos que procuram apresentar indícios de bolhas racionais nos preços das habitações brasileiras. Baseando-se no modelo de bolhas racionais descrito por Besarria (2014), a metodologia proposta para captar a relação entre os preços dos ativos e seus valores fundamentais é dada pelos processos cointegrados lineares e com quebra estrutural. 
O primeiro passo para o estabelecimento da cointegração é dado pelos testes de estacionariedade das séries. ${ }^{4}$ Para esse fim, são aplicados os testes Dickey-Fuller aumentado, de Kwiatkowski, Phillips, Schmidt e Shin (KPSS) e de Phillips-Perron (PP). Visto que, conforme destaca Bueno (2011), o teste proposto por Dickey e Fuller (1981) não consegue rejeitar a hipótese de estacionariedade para uma infinidade de séries econômicas, por essa razão utiliza-se o teste KPSS, que tem o propósito de distinguir a raiz unitária de séries cujos dados não são suficientemente conclusivos.

O passo seguinte é verificar se as séries de preços das habitações e os preços do aluguel são cointegrados. O conceito de cointegração refere-se à ligação entre processos integrados e o equilíbrio no estado estacionário, e a existência de um equilíbrio de longo prazo significa dizer que as variáveis não se movem de forma independente e que não há indícios de bolhas nos preços dos ativos.

As metodologias mais tradicionais para testar a cointegração são: Engle e Granger (1987) e Johansen e Juselius (1990). A primeira metodologia afirma que as variáveis em estudo serão cointegradas se forem integradas de mesma ordem (sendo ) e se existir uma combinação linear dessas variáveis que seja estacionária. Essa técnica não é indicada para testar a cointegração quando existe a possibilidade da existência de mais de um vetor de cointegração. Nesse caso, a metodologia recomendada é a de Johansen e Juselius (1990).

No entanto, fatores como crises, mudanças na estrutura regulatória, políticas fiscais e monetárias podem fazer com que duas variáveis passem a se comportar de modo diferente em um dado momento do tempo, alterando ou não a relação de longo prazo entre essas. Essa mudança ocorrida na tendência ou trajetória das séries é conhecida na literatura como quebra estrutural, e a presença desse componente pode invalidar os testes de cointegração de Engle e Granger (1987) e Johansen e Juselius (1990).

Autores como Bierens (1997a, 1997b) e Nunes e Silva (2009) destacam que os testes de cointegração convencionais podem não ser apropriados na identificação de bolhas, visto que esses testes consideram que o processo de ajustamento é simétrico sem levar em consideração o fato de que a verdadeira natureza do processo de ajustamento pode ser não linear ou, até mesmo, ter apresentado mudança estrutural na relação de cointegração entre as séries. Com base nessas hipóteses, foi utilizado o teste de cointegração com quebra estrutural proposto por Gregory e Hansen (1996).

A discussão subsequente está baseada na análise dos efeitos dos choques (bolhas) nos preços das habitações sobre os instrumentos de política monetária e

$4 \quad$ Morettin (2008) estabelece que um processo $X_{t}$ é integrado de ordem $d$ se $\Delta^{d} X_{t}$ for estacionário, representando-o por $X_{t} \sim \mathrm{I}(d)$. Portanto, para uma série que apresenta o seguinte comportamento $X_{t}=\Psi X_{t-1}+\varepsilon_{t}$, tem-se que a série é não estacionária quando $\Psi=1$, sendo que a série é estacionária quando $\Psi<1$. 
fiscal, por meio do modelo de vetores autorregressivos (SVAR), sendo analisada a resposta dessas variáveis ao impulso ou choque exógeno. Como descrito em Besarria, Paes e Silva (2014), autores como Faust (1998), Canova e Nicoló (2002) e Uhlig (2005) propõem um esquema de identificação que impõe restrições de sinal sobre as respostas estruturais. A estratégia reconhece que há um número infinito de mapeamentos equivalentes entre os erros na forma reduzida e estrutural, e a ideia da restrição sinal é selecionar um subconjunto desses mapeamentos que são consistentes com determinadas características qualitativas.

Com base nisso, este artigo utiliza a abordagem de identificação por meio de restrições de sinais proposta por Uhlig (2005). Inicialmente, o modelo VAR na forma estrutural pode ser representado por

$$
A Z_{t}=\sum_{i=1}^{p} A_{i} Z_{t-i}+\varepsilon_{t} \quad \text { para } \quad t=0: T
$$

Assumindo que é não singular, então a equação 1, na sua forma reduzida, pode ser representada por

$$
Z_{t}=\sum_{i=1}^{p} B_{i} Z_{t-i}+u_{t}
$$

em que $B_{i}=A_{i} A^{-1}$ para $i=1,2, \ldots, p, u_{t}=\varepsilon_{t} A^{-1}$.

Define-se $Z_{t}$ como um vetor $(8,1)$ das variáveis macroeconômicas, no qual $\prod_{t}, y_{t}, r_{t}, p h_{t}, R c_{t}, D s_{t}, h_{t}$ e Fn $n_{t}$, representam, respectivamente, IPCA, PIB, taxa Selic, preços habitacionais, receita total/PIB, despesa total/PIB, horas trabalhadas e financiamento habitacional, sendo representado por: $Z_{t}=\left[\prod_{t}, y_{t}, r_{t}, p h_{t}, R c_{t}, D s_{t}, h_{t}, F n_{t}\right]$ '.

Neste artigo, o modelo VAR na sua forma reduzida é estimado para os dados da economia brasileira, utilizando a estratégia de identificação de restrição de sinais proposta por Uhlig (2005). É importante destacar que, diferentemente da discussão proposta por Uhlig (2005), na qual este procurou analisar os efeitos de um choque contracionista na política monetária, este artigo se concentra no exercício de identificação em um conjunto limitado de variáveis que interagem com o choque positivo nos preços das habitações brasileiras.

Dessa forma, o método proposto por Uhlig (2005) consiste em mostrar que a matriz de relação contemporânea $A$ na equação 1 , tal que $\widehat{\Sigma}=A A^{\prime}$, pode ser definida por $A=\tilde{A} Q$, sendo que $Q$ é uma matriz ortogonal $\left[Q Q^{\prime}=I\right]^{5}$ e $\tilde{A}$ é a decomposição de Cholesky da matriz estimada de variância dos resíduos $\widehat{\Sigma}$. Esse fato nos leva à identificação de uma única coluna $a$ da matriz $A$ na equação 1 . Com isso, o problema se limita à determinação de um vetor $a$, associado ao vetor $m$-dimensional $\alpha$ de comprimento unitário, de modo que

$5 \quad$ Ver Faust (1998) e Uhlig (1998).

BESSARIA, C. N. Choques nos Preços dos Ativos e a Dinâmica das Decisões de Políitica... 


$$
a=\tilde{A} \alpha
$$

Como já descrito, é uma coluna de denominada por Uhlig (2005) de vetor impulso que contém as respostas contemporâneas das variáveis endógenas a um determinado choque, sendo que é vetor coluna de referente à posição correspondente. Como descrito por Uhlig (2005), dado o vetor impulso, é possível calcular a resposta ao impulso apropriado admitindo que $r_{i}(\mathrm{k})$ seja o impulso-resposta no período k do i-ésimo choque obtido da decomposição de Cholesky. O impulso-resposta para k períodos é representado por

$$
r_{a}(k)=\sum_{i=1}^{m} \alpha_{i} r_{i}(k)
$$

A expressão 4 mostra que é possível identificar o vetor de impulso correspondente ao choque nos preços dos ativos. Por fim, destaca-se que a fração $\varnothing_{\mathrm{a}, \mathrm{j}, \mathrm{k}}$ da variância da revisão de previsão para a variável j, explicada pelo choque na direção do vetor de impulso $a$, é dada por

$$
\emptyset_{a, j, k}=\frac{\left(r_{a, j}(k)\right)^{2}}{\sum_{i=1}^{m}\left(r_{i, j}(k)\right)^{2}}
$$

em que o índice $\mathrm{j}$ adicional representa a entrada correspondente à variável j. Com essas ferramentas, pode-se realizar a decomposição da variância ou experimentos contrafactuais.

\subsection{Base de Dados}

Para a primeira etapa empírica (análise de cointegração) foi utilizada a base de dados composta por observações mensais do preço de venda e locação das habitações brasileiras, sendo o aluguel representado pelo IGPM. Essas séries foram coletadas, respectivamente, no Bank for International Settlements (BIS) e na Fundação Getúlio Vargas (FGV), compreendendo o período de março de 2001 a outubro de 2013. Destaca-se que a seleção dessas variáveis se deu com base nos trabalhos de Himmelberg, Mayer e Sinai (2005) e Kivedal (2013), os quais mostram que a relação entre os preços da habitação e o preço do aluguel pode ser utilizada para investigar a existência de uma bolha no mercado imobiliário. Em relação à escolha do período de análise, ela se deu pela disponibilidade dos dados.

Algumas ponderações em relação à base de dados devem ser feitas: primeiro, a Fundação Instituto de Pesquisas Econômicas (Fipe) possui um banco de dados mensal, referente ao mercado habitacional brasileiro, compreendendo o período de janeiro de 2008 a setembro de 2013 . No entanto, a dimensão temporal 
da amostra para a série do composto nacional do preço de venda (índice FipeZap composto representa a soma das participações regionais) não compreende todo o período de 2001 a outubro de 2013, apresentando menos de 60 observações, fator que compromete os resultados obtidos na análise; segundo, em relação ao índice de preço dos aluguéis, foi utilizado o IGPM como proxy, visto que é o índice utilizado para a correção de contratos de aluguel.

Em relação à discussão dos efeitos nos choques dos preços nas variáveis fiscais e monetárias, foram utilizadas as observações trimestrais do PIB, receita e despesa total, taxa Selic, financiamento habitacional, inflação, preços habitacionais, consumo das famílias e horas trabalhadas no período de março de 2001 a dezembro de 2013. Em relação ao tratamento inicial dessas séries, destaca-se que foi realizado o ajuste sazonal por meio do método X11-Arima, e as séries do PIB e IPCA foram tratadas em termos de desvios de sua tendência. ${ }^{6} \mathrm{O}$ Quadro 1 descreve as variáveis utilizadas neste artigo e sua respectiva fonte.

Quadro 1 - Descrição das variáveis

\begin{tabular}{|c|c|c|}
\hline Variável & Descrição & Fonte \\
\hline PIB & $\begin{array}{l}\text { PIB, preços de mercado, índice encadea- } \\
\text { do (média } 1995=100 \text { ). }\end{array}$ & IBGE \\
\hline $\begin{array}{l}\text { Receita total/ } \\
\text { PIB }\end{array}$ & $\begin{array}{l}\text { Execução financeira, receitas, total - em } \\
\mathrm{R} \$ \text { (milhões) - deflacionado pelo IPC. }\end{array}$ & $\begin{array}{l}\text { Ministério da } \\
\text { Fazenda }\end{array}$ \\
\hline $\begin{array}{l}\text { Despesa total/ } \\
\text { PIB }\end{array}$ & $\begin{array}{l}\text { Execução financeira, despesas, total - em } \\
\mathrm{R} \$ \text { (milhões) - deflacionado pelo IPC. }\end{array}$ & $\begin{array}{l}\text { Ministério da } \\
\text { Fazenda }\end{array}$ \\
\hline $\begin{array}{l}\text { Horas traba- } \\
\text { lhadas }\end{array}$ & $\begin{array}{l}\text { Horas trabalhadas na indústria: índice } \\
\text { dessazonalizado (média } 2006=100 \text { ). }\end{array}$ & Ipeadata \\
\hline $\begin{array}{l}\text { Financiamen- } \\
\text { to habitacio- } \\
\text { nal/PIB }\end{array}$ & $\begin{array}{l}\text { Financiamentos imobiliários para aquisi- } \\
\text { ção de imóveis residenciais novos - em } \\
\mathrm{R} \$ \text { (milhões) - deflacionado pelo IPC. }\end{array}$ & $\begin{array}{l}\text { Estatísticas bási- } \\
\text { cas (SBPE-SFH/ } \\
\text { BCB) }\end{array}$ \\
\hline Taxa Selic & $\begin{array}{l}\text { Taxa média ajustada dos financiamentos } \\
\text { diários apurados no Sistema especial de } \\
\text { liquidação e de custódia (Selic) para títu- } \\
\text { los federais. }\end{array}$ & $\mathrm{BCB}$ \\
\hline $\begin{array}{l}\text { Preços habita- } \\
\text { cionais }\end{array}$ & $\begin{array}{l}\text { Índice de preços reais dos imóveis } \\
\text { residenciais. }\end{array}$ & $\begin{array}{l}\text { Bank for Inter- } \\
\text { national Settle- } \\
\text { ments }\end{array}$ \\
\hline IPCA & $\begin{array}{l}\text { Índice nacional de preços ao consumidor } \\
\text { amplo. }\end{array}$ & IBGE \\
\hline
\end{tabular}

Fonte: Elaboração própria.

6 As tendências do PIB e da inflação foram calculadas a partir do procedimento de suavização denominado de filtro de Hodrick-Prescott (HP), sendo adotado parâmetro de suavização igual a 1.600 . 
Ressalta-se que a série de venda dos imóveis foi coletada no BIS e representa os preços dos imóveis das regiões metropolitanas, com abrangência nacional.

\section{Discussão dos Resultados}

Nesta seção são apresentadas as discussões sobre os métodos propostos para a análise de bolhas nos preços das habitações brasileiras. No Gráfico 2 são apresentadas as séries mensais dos índices de preços de venda e aluguel das habitações no período de março de 2001 a outubro de 2013.

Gráfico 2 - Índice de preços habitacionais e índice de preço do aluguel (IGPM)

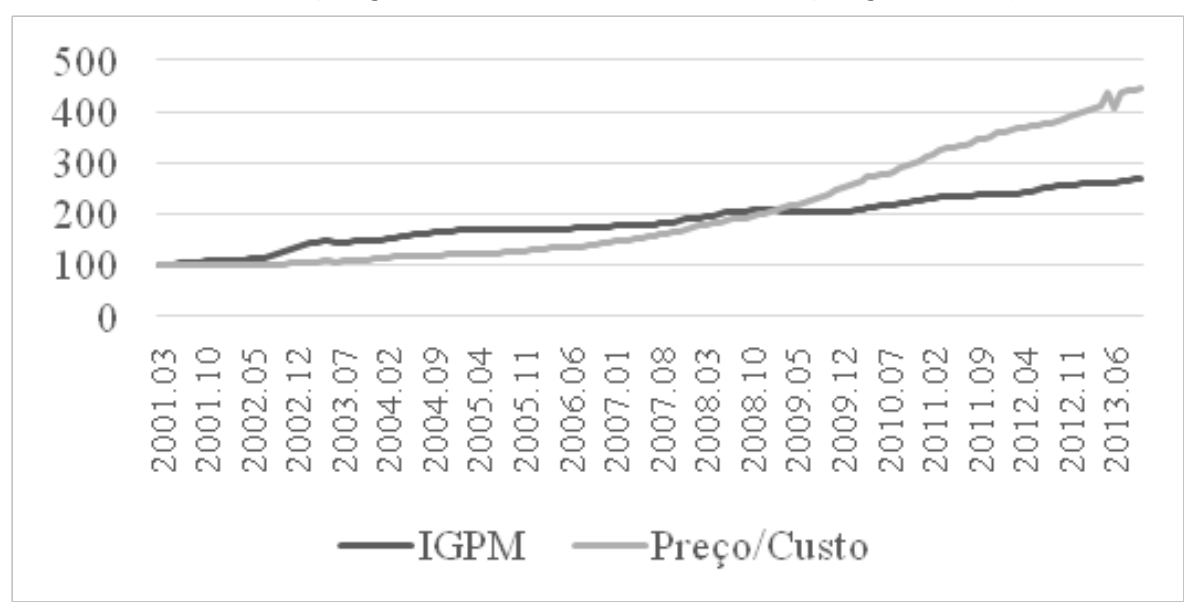

Fonte: Elaboração própria a partir de Secovi-SP (2015).

Informalmente, ao se analisar o Gráfico 2, é possível verificar que o preço médio de venda das habitações e o valor médio do aluguel apresentaram forte valorização a partir de 2008 e que os preços das habitações passaram a apresentar uma taxa de crescimento superior ao fluxo de dividendos. Salienta-se que fatores conjunturais, tais como crescimento do PIB, crédito habitacional, renda disponível, taxas de juros subsidiadas, realização de eventos internacionais, como a Copa do Mundo em 2014 e as Olimpíadas em 2016, podem ter contribuído para a valorização desses imóveis. Porém, a experiência recente dos Estados Unidos mostrou que, além desses fatores, é possível que os preços das habitações sejam influenciados pelo surgimento de bolhas.

A discussão empírica proposta para testar o modelo de bolhas racionais, definido por Gilles e LeRoy (1992), é dada pela análise dos comovimentos dinâmicos entre as séries de preços de venda das habitações e os preços do aluguel. Para o caso de haver bolhas racionais, é esperado que essas séries não apresentem uma 
tendência estocástica comum de longo prazo, isto é, sejam não cointegradas e, para o caso de as séries serem cointegradas, então é válido o modelo de valor presente.

Como pré-requisito para a análise de cointegração, foram aplicados os testes de estacionariedade Dickey-Fuller aumentado, KPSS e PP a fim de se verificar a estacionariedade e a ordem de integração das variáveis utilizadas. Como pode ser visto no Quadro 2, para o caso analisado os três testes mostraram que as séries de preço de venda e aluguel das habitações possuem raiz unitária (não estacionária) em nível. Por sua vez, encontram-se evidências de que as séries são estacionárias em primeira diferença ao não se rejeitar a hipótese de estacionariedade a 5\%.

Quadro 2 - Testes de raiz unitária de Dickey-Fuller aumentado, PP e KPSS

\begin{tabular}{|c|c|c|c|c|c|c|}
\hline \multirow[t]{2}{*}{ Série } & \multicolumn{2}{|c|}{$\begin{array}{c}\text { Teste de raiz } \\
\text { unitária (Dickey- } \\
\text { Fuller) }\end{array}$} & \multicolumn{2}{|c|}{$\begin{array}{l}\text { Teste de Phillips- } \\
\text { Perron (PP) }\end{array}$} & \multicolumn{2}{|c|}{$\begin{array}{l}\text { Testes de estaciona- } \\
\text { riedade de Kwiatko- } \\
\text { wski-Phillips-Schmi- } \\
\text { dt-Shin (KPSS) }\end{array}$} \\
\hline & $\mathrm{t}_{\alpha}$ & $t_{\text {critico }}$ & $\hat{z}_{\mu}$ & $\mathrm{Z}_{\mu}^{* * *}$ & $\hat{\eta}_{\mu}$ & $\eta_{\mu}{ }^{* * * *}$ \\
\hline Preço $_{t}$ & 2.53 & $-2,89$ & 7.52 & $-3,45$ & 1.90 & 0.15 \\
\hline$\Delta$ PreçO $_{t}$ & -7.68 & $-2,89$ & -18.92 & $-3,45$ & 0.08 & 0.15 \\
\hline IGPM $_{t}$ & -0.40 & $-2,89$ & -0.43 & $-3,45$ & 0.54 & 0.15 \\
\hline$\Delta \mathrm{IGPM}_{\mathrm{t}}$ & -5.15 & $-2,89$ & -5.46 & $-3,45$ & 0.15 & 0.21 \\
\hline
\end{tabular}

Fonte: Elaboração própria.

Nota: $\left({ }^{*}\right),\left({ }^{* *}\right),(* * *)$ representam valores críticos ao nível de $5 \%$; todos os testes foram realizados levando em consideração a constante e a tendência; a hipótese nula dos testes Dickey-Fuller aumentado e PP representa não estacionariedade das séries, diferentemente do teste KPSS.

Depois de se verificar que as séries apresentaram a mesma ordem de integração, se implementou o teste de cointegração de Johansen. Como pode ser visto no Quadro 3, identificou-se, por meio do modelo linear com intercepto e tendência determinística quadrática, que não existe relação de cointegração entre as séries para o período analisado, tanto pelos testes do máximo autovalor quanto pelo teste do traço, indicando a existência de uma bolha no mercado habitacional brasileiro. 
Quadro 3 - Teste de cointegração de Johansen

\begin{tabular}{|c|c|c|c|c|}
\hline \multicolumn{5}{|c|}{ Testes de cointegração irrestrito (traço) } \\
\hline $\begin{array}{c}\text { Número de equa- } \\
\text { ções de cointegração }\end{array}$ & Autovalor & $\begin{array}{c}\text { Estatística do } \\
\text { traço }\end{array}$ & $\begin{array}{c}\text { Valores } \\
\text { críticos a } \\
5 \%\end{array}$ & Probabilidade \\
\hline Zero & 0.06 & 9.62 & 18.39 & 0.51 \\
\hline No máximo 1 & 0.001 & 0.18 & 3.84 & 0.67 \\
\hline \multicolumn{4}{|c|}{ Testes de cointegração irrestrito (traço) } \\
\hline $\begin{array}{c}\text { Número de equa- } \\
\text { ções de cointegração }\end{array}$ & Autovalor & $\begin{array}{c}\text { Estatística } \\
\text { do autovalor } \\
\text { máximo }\end{array}$ & $\begin{array}{c}\text { Valores } \\
\text { críticos a } \\
5 \%\end{array}$ & Probabilidade \\
\hline Zero & 0.06 & 9.44 & 17.14 & 0.45 \\
\hline No máximo 1 & 0.001 & 0.18 & 3.84 & 0.67 \\
\hline
\end{tabular}

Fonte: Elaboração própria.

Nota: (*) A aceitação da hipótese nula do teste do traço indica não cointegração das séries; os p-valores foram obtidos a partir de MacKinnon, Haug e Michelis (1999). O teste incluiu intercepto e tendência determinística quadrática, utilizando dois lags em primeira diferença, definidos a partir dos critérios AIC e SBC.

No entanto, como já descrito, o teste convencional de cointegração proposto por Johansen não consegue captar a verdadeira natureza do processo de ajustamento das séries quando esse processo é dado de forma não linear ou quando há mudança de regime. Ao se analisar os resultados obtidos pelo teste de cointegração com quebra estrutural proposto por Gregory-Hansen (1996), é possível verificar que o valor calculado da estatística $Z_{\alpha}^{*}(\mathrm{C} / \mathrm{S})$ foi inferior ao valor crítico ao nível de $95 \%$ de significância, representando que a hipótese nula de não cointegração foi aceita e que houve mudança estrutural na relação dos preços das habitações e seus dividendos no ano de 2008 (ver Quadro 4).

Quadro 4 - Teste de cointegração com quebra estrutural proposto por Gregory-Hansen (1996)

\begin{tabular}{|c|c|c|}
\hline $\mathbf{Z}_{\alpha}^{*}(\mathbf{C} / \mathbf{S})$ & $\mathbf{9 5 \%}$ & Data da quebra estrutural \\
\hline $\mathbf{- 4 . 9 8 6}$ & -5.470 & $2008: 02$ \\
\hline
\end{tabular}

Fonte: Elaboração própria.

Dentre os fatores que podem ter influenciado a mudança de regime na relação dos preços das habitações e seus dividendos, como pode ser visto na Gráfico 3, destaca-se o anúncio do lançamento do Programa de Aceleração do Crescimento (PAC) para janeiro de 2007, tendo como um dos principais objetivos o aumento do volume de crédito destinado ao setor habitacional. 


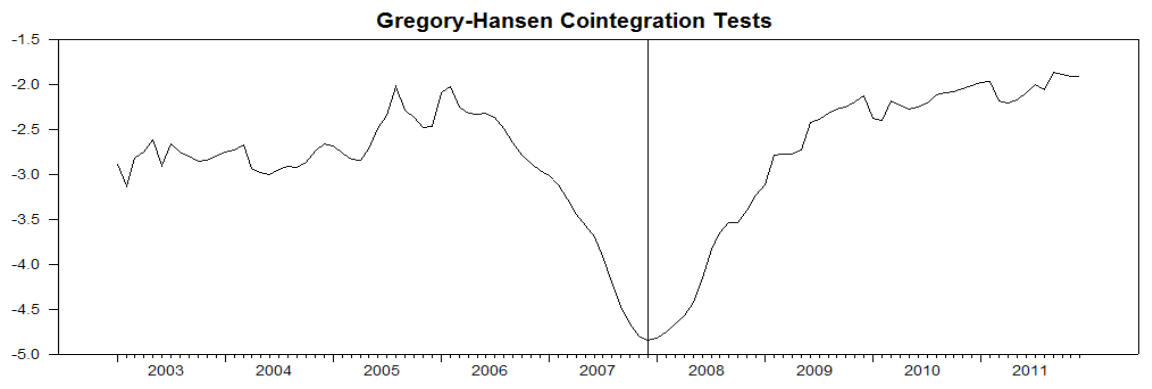

Fonte: Elaboração própria.

Essa análise apresenta evidências que dão suporte à hipótese de que os preços das habitações brasileiras têm sido impulsionados, em parte, por uma bolha racional, 7 na qual o preço desse ativo diverge do seu valor intrínseco. A importância dessa análise fica mais evidente quando são tratados os efeitos monetários e fiscais desse choque.

Após mostrar que há indícios de uma bolha no mercado de habitações brasileiro, surge o seguinte questionamento: qual o risco que o aumento nos preços das habitações pode trazer para a economia brasileira? A resposta para esse questionamento, apesar de não ser simples, pode ser analisada por diversos aspectos. Um deles é que o maior problema não está no aumento, mas sim na redução dos preços. ${ }^{8} \mathrm{O}$ que se verificou, por exemplo, na economia americana durante a crise subprime foi que, conforme descreve Silver (2013), por volta de 2007 os americanos de classe média tinham mais de $65 \%$ do seu patrimônio vinculado às suas casas. Com a redução dos preços das habitações, as famílias se tornaram mais pobres e se encontravam em uma situação bem pior que antes da crise.

Em relação à economia brasileira, percebe-se que as habitações representam um dos principais ativos das famílias. Conforme dados do Censo 2010, o número total de domicilios particulares próprios corresponde a 42.009 milhões. Isso mostra que $68,1 \%$ das famílias brasileiras possuem domicílio próprio ou estão em processo de aquisição (5,2\%) e 18,3\% se enquadram nas condições de alugado (ver Gráfico 4).

$7 \quad$ A teoria das finanças comportamentais assume outra definição para bolha, sendo definida como bolha especulativa. Ela se desenvolve a partir da assimetria de informação presente no mercado e potencializada por falhas cognitivas cometidas pelos agentes que atuam nesse mercado.

8 Muellbauer (1994) mostra que o aumento nos preços habitacionais apresenta efeitos ambíguos: efeito positivo (efeito riqueza) e efeito negativo de preços relativos (compostos pelos efeitos rendimento e substituição). 
Gráfico 4 - Distribuição do número total dos domicílios brasileiros

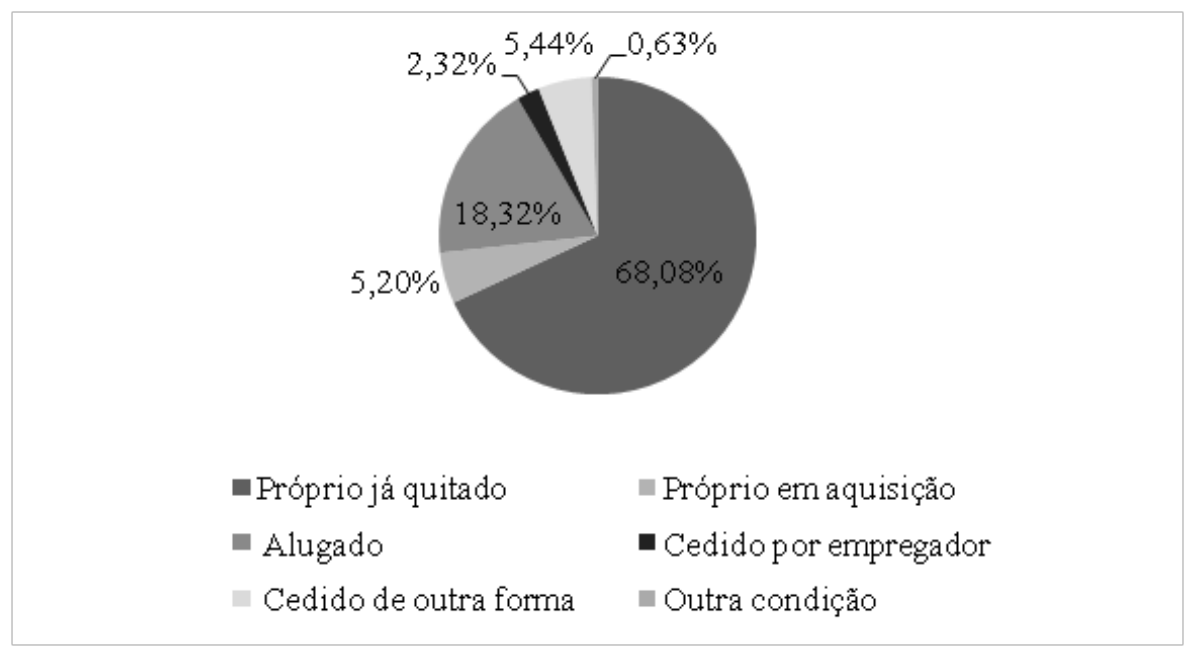

Fonte: Elaboração própria a partir de IBGE (2014).

Quando se compara esses números com outras alternativas de investimento de renda variável, tais como ações, percebe-se que o aumento ou redução nos preços das habitações trará efeitos bem mais representativos no patrimônio dessas famílias que flutuações nos preços de ativos como ações. Por exemplo, Leister (2011) mostra que, no período entre 2000 e 2009, houve crescimento de $620 \%$ na quantidade de investidores pessoa física que possuem ações ou outros ativos passíveis de negociação na bolsa de valores, mas esses investidores representam apenas $0,3 \%$ da população brasileira.

Devido ao fato de a habitação constituir um dos principais componentes da riqueza das famílias, as alterações nos preços poderão ter um impacto significativo sobre a percepção das famílias em relação à sua riqueza e rendimento permanente, bem como sobre as suas possibilidades de endividamento. Isso se dá devido ao fato de o ativo habitacional possuir características, tais como existência de estoque, fixação espacial, alto custo de aquisição, longa vida útil e longo período de produção que, como destaca Mishkin (2007), torna o efeito sobre o consumo derivado de mudanças na riqueza imobiliária maior que o derivado de outros ativos, particularmente das ações. Para o caso americano, Silver (2013) destaca que a queda no consumo foi avaliada entre $1,5 \%$ e 3,5\% do PIB ao ano. Nesse sentido, Pacheco e Barata (2006) apresentam uma série de estudos, sumarizados no Quadro 5 , que procuraram estimar as propensões marginais ao consumo, associadas ao comportamento dos mercados acionário e imobiliário. 


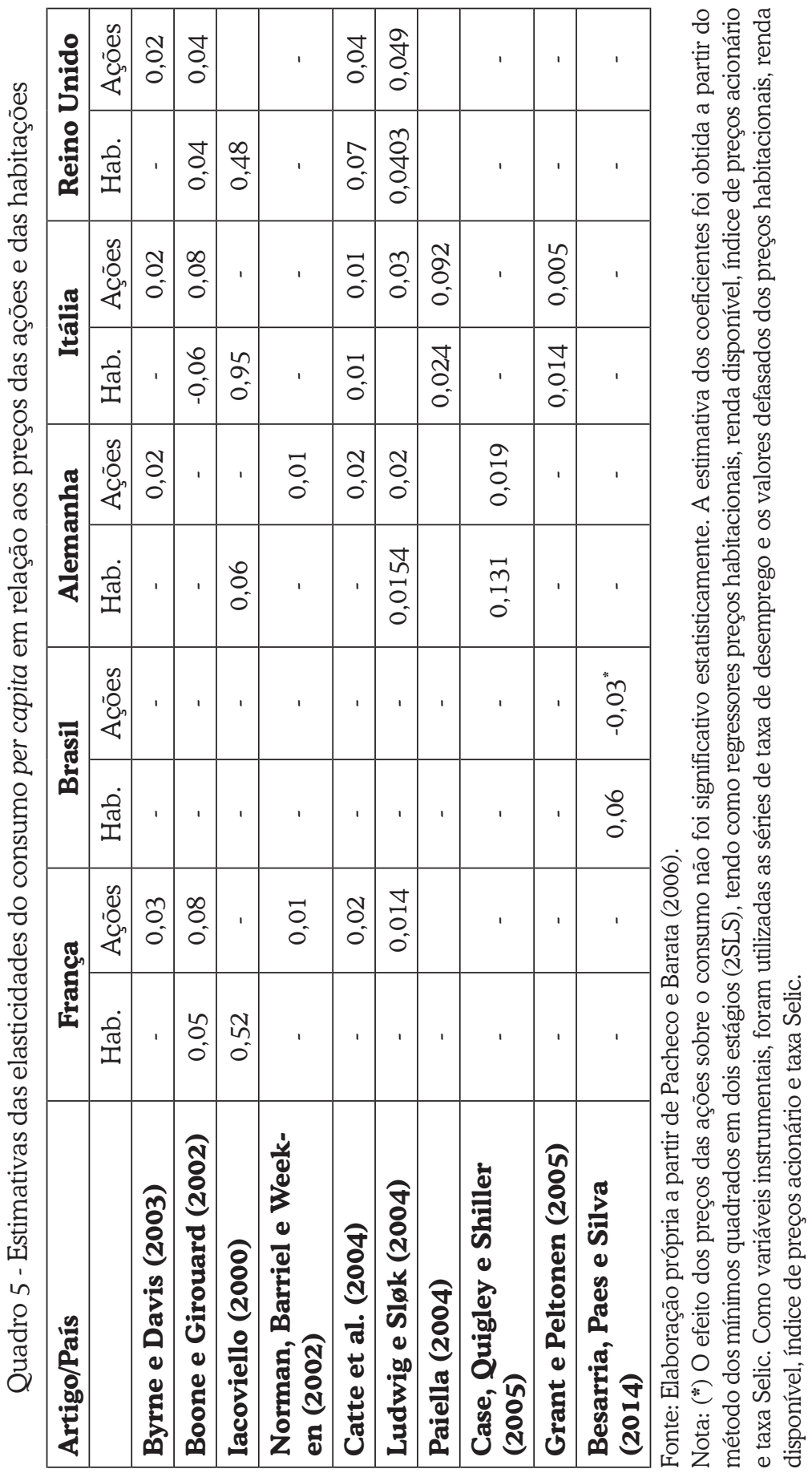


Como pode ser visto, para o caso brasileiro é possível verificar que a estimativa dos efeitos das elasticidades do consumo per capita em relação aos preços das habitações evidenciou que a riqueza associada à habitação exerce influência positiva sobre o consumo das famílias. Destaca-se que os efeitos encontrados para as variações do consumo derivados das variações nos preços das habitações se assemelham aos resultados encontrados por Iacoviello (2000), Boone e Girouard (2002) e Catte et al. (2004) para as economias da Alemanha, França e Reino Unido, respectivamente, sendo que a renda disponível foi o fator que desempenhou maior impacto na explicação das variações no consumo. É importante ressaltar que os financiamentos imobiliários na economia brasileira são na modalidade de alienação fiduciária (e não hipoteca, como no caso americano). Assim, a legislação brasileira não permite uma segunda hipoteca sobre a alienação fiduciária, fato que certamente diminui o efeito riqueza do imóvel sobre o consumo.

Em relação ao mercado acionário, verifica-se que alterações nos preços desses ativos não apresentaram efeitos significativos sobre o consumo das famílias brasileiras. Em relação ao questionamento inicial proposto nesta seção, outros argumentos surgirão ao longo do texto e que procurarão evidenciar os riscos para a economia brasileira provenientes do aumento e/ou redução nos preços das habitações. Dentre esses serão destacados os efeitos do aumento dos preços das habitações nas contas públicas e a resposta que vem sendo dada pelo Banco Central a esses choques.

\subsection{Bolhas de Ativos e seus Efeitos Fiscais e Monetários}

Nesta seção são apresentados os efeitos dos choques nos preços das habitações no comportamento das séries da inflação, PIB real, consumo das famílias, taxa Selic, receita e despesa governamental, mercado de trabalho e financiamento habitacional. Como descrito anteriormente, os efeitos desse choque serão analisados por meio do esquema de identificação que impõe restrições de sinal sobre as respostas estruturais do modelo SVAR proposto por Uhlig (2005). Destaca-se que as funções impulso-resposta foram obtidas por meio do modelo VAR com uma defasagem, definido a partir do critério de informação Akaike.

O Gráfico 5 representa os efeitos do choque positivo nos preços das habitações sobre a taxa de juros, inflação, produto real, financiamento habitacional, receita e despesa governamental, consumo das famílias e horas trabalhadas. É importante ressaltar que o choque positivo e exógeno nos preços dos ativos é interpretado, por autores como Besarria, Silva e Paes (2014), Wang e Wen (2012), Ratto, Roeger e Veld (2010), Funke, Paetz e Pytlarczyk (2011), Miao, Wang e Xu (2013), Bernanke e Gertler (1999) e Bernanke e Gertler (2001), como componente 
bolha, sendo que a função impulso-resposta do choque nos preços das habitações é não negativa, sendo observado o comportamento das demais variáveis.

Gráfico 5 - Resposta ao choque nos preços das habitações
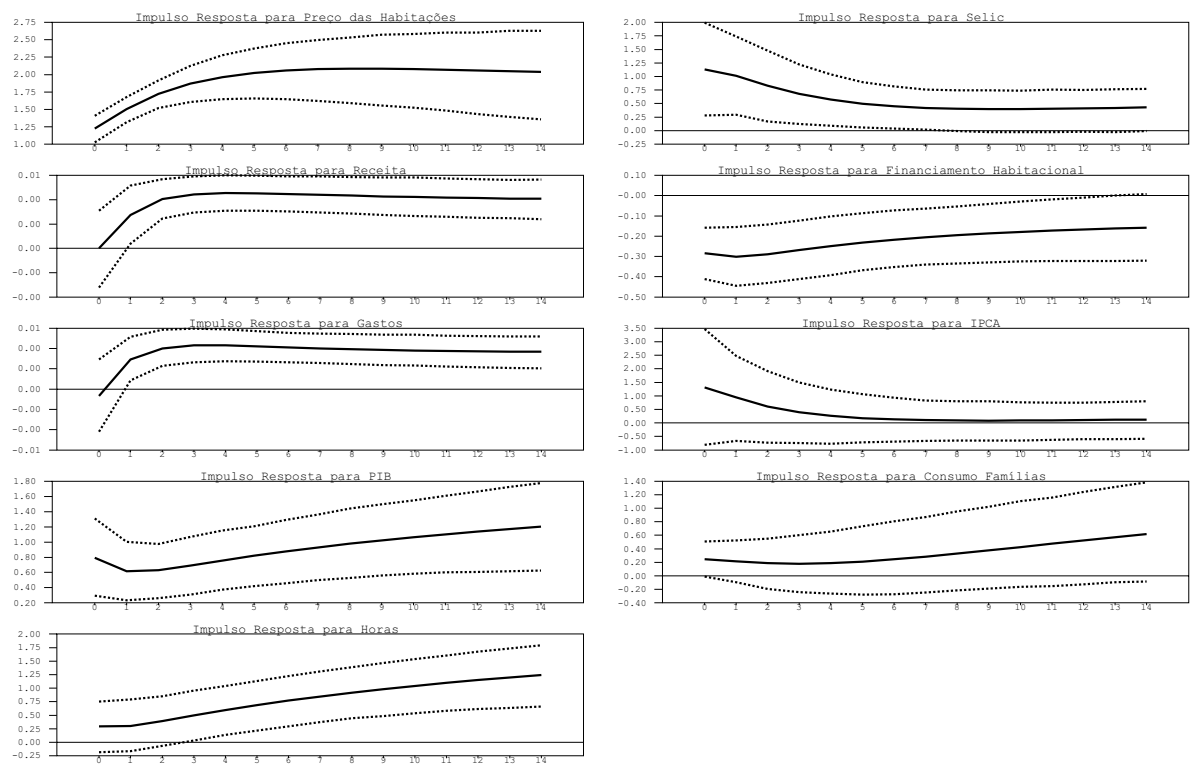

Fonte: Elaboração própria.

Nota: As linhas pontilhadas representam as bandas de probabilidade entre 0.16 e 0.84 , com horizonte de tempo de 10 trimestres e restrição de sinal pura para cinco trimestres, sendo eliminadas subsequentemente.

Como pode ser observado no Gráfico 5, o choque positivo nos preços das habitações foi acompanhado do aumento no número de horas trabalhadas, receita e gastos do governo, taxa Selic, inflação, PIB e consumo das famílias.

\subsubsection{Discussão dos Efeitos Fiscais}

Inicialmente é importante destacar que a compreensão da transmissão dos efeitos de uma bolha nos preços dos ativos sobre a política fiscal é limitada e que ainda não há na literatura uma discussão aprofundada sobre essa temática. Como proposta, este artigo analisa os efeitos desse choque por meio dos canais monetários e fiscais.

Em relação à resposta fiscal, verifica-se que o aumento nos preços das habitações brasileiras trouxe efeitos permanentes nas receitas e nos gastos do governo. Esse canal ainda não foi muito explorado pela literatura, e o que se faz neste estudo é um esforço para se mostrar alguns dos efeitos que a expansão nos preços dos 
imóveis pode trazer sobre o orçamento governamental. Assim, ao se realizar uma análise específica dos efeitos fiscais das habitações na arrecadação tributária dos municípios, percebe-se que houve uma expansão significativa no imposto sobre a transmissão de bens imóveis (ITBI) e no imposto predial e territorial urbano (IPTU) após a implantação do programa Minha Casa, Minha Vida e a expansão nos preços das habitações ocorrida a partir do ano de 2007.

Quadro 6 - Carga tributária municipal ligada ao setor habitacional ( $\mathrm{R} \$$ milhões)

\begin{tabular}{|c|c|c|c|c|c|c|c|}
\hline Imposto & $\mathbf{2 0 0 7}$ & $\mathbf{2 0 0 8}$ & $\mathbf{2 0 0 9}$ & $\mathbf{2 0 1 0}$ & $\mathbf{2 0 1 1}$ & $\mathbf{2 0 1 2}$ & $\boldsymbol{\Delta} \%$ \\
\hline IPTU & 12.628 & 13.545 & 14.882 & 17.152 & 19.334 & 21.174 & 68 \\
\hline ITBI & 3.467 & 4.324 & 4.546 & 5.919 & 7.369 & 8.406 & 142 \\
\hline
\end{tabular}

Fonte: Elaboração própria a partir de Secretaria da Receita Federal do Brasil (2015).

Em relação ao IPTU, este tem como fato gerador a propriedade localizada na zona urbana do município, cuja base de cálculo é o valor venal do imóvel. Como pode ser visto em cinco anos, a arrecadaão do IPTU cresceu $68 \%$, passando de 12.628 milhões para 21.174 milhões. Apesar da expansão da arrecadação do IPTU, não é possível explicitar a parcela da contribuição dos imóveis e do reajuste do valor venal dos imóveis. Porém, provavelmente boa parte do aumento do IPTU veio dos imóveis novos, tendo em vista que o preço venal, para fins de IPTU, dificilmente é atualizado continuamente pelas secretarias de fazenda das prefeituras.

Ao se analisar o imposto que incide sobre a compra e venda de imóveis, o ITBI, cuja base de cálculo é o valor venal dos bens ou direitos transmitidos, em média os municípios adotam uma alíquota de aproximadamente $2 \%$, então se percebe que houve um aumento de 142\% na arrecadação desse imposto.

Esse resultado sugere que a apreciação dos ativos imobiliários estimula a atividade fiscal do estado em um comportamento pró-cíclico, promovendo ganhos de arrecadação aos governos municipais, e, em virtude desse aumento, os governos passam a gastar mais.

Esse cenário passa a representar um problema no momento da reversão dos preços das habitações. Esse desenho de política fiscal pode vir a contribuir com a instabilidade da atividade econômica. Uma vez que as evidências empíricas sugerem que no caso de uma perda de receita, ocasionada, por exemplo, pela reversão nos ciclos dos preços dos ativos, os gastos do governo seriam menos sensíveis a essa reversão que a receita governamental, podendo ocasionar déficits orçamentários.

Esse fato é destacado por Besarria (2014), que verifica que, a partir de 2006, período em que sucedeu a ruptura da bolha da habitacional americana, a condução da política fiscal dos países desenvolvidos apresentou diferenças marcantes 
em relação aos períodos anteriores, caracterizando-se pelos desequilíbrios fiscais e pelo aumento das vulnerabilidades externas.

Foi possível verificar que nesse período as receitas do governo geral do Japão, Reino Unido e Estados Unidos representavam, respectivamente, 30,8\%, 38\% e $33,8 \%$ do PIB, em 2006, e passou para 30,6\%, 37,1\% e 31,8\% em 2011, respectivamente. Por outro lado, houve um aumento significativo nas despesas desses países, que passaram de 34,5\%, 40,6\% e 35,9 do PIB, em 2006, para 40,7\%, 45,7\% e 41,4\%, no Japão, Reino Unido e Estados Unidos, respectivamente, sinalizando que esse fato foi verificado com crescimento das despesas e redução da arrecadação após a ruptura da bolha imobiliária.

\subsubsection{Discussão dos Efeitos Monetários}

A discussão dos efeitos monetários causados pela expansão dos preços das habitações pode ser representada pela seguinte sequência: efeito riqueza positivo sobre o consumo, PIB real e, conjuntamente com os efeitos fiscais, esse choque afeta positivamente o mercado de trabalho, a inflação e a taxa de juros. É importante fazer uma ressalva em relação ao efeito riqueza decorrente da valorização dos imóveis no Brasil. Tal como já enfatizado, a modalidade de alienação fiduciária não permite uma segunda hipoteca no Brasil. Além disso, a possibilidade de portabilidade de dívida é muito recente, fato que não permite captar a materialização desse mecanismo no efeito riqueza.

Feita essa advertência, destaca-se que essa análise se diferencia da proposta por Mishkin (2007), que avalia os efeitos de forma direta e indireta dos choques de política monetária sobre o mercado habitacional através dos seguintes canais: a) custo de utilização do capital; b) expectativas de movimentos futuros nos preços dos imóveis; c) oferta de habitação; d) efeito riqueza sobre os preços das habitações; e) canal de crédito sobre os gastos dos consumidores; e f) canal de crédito na demanda por habitações.

Como pode ser visto, os efeitos do choque apresentado na Figura 1 são bastante intuitivos, então se percebe que o aumento nos preços das habitações trouxe efeitos positivos e permanentes sobre o consumo das famílias e o PIB real. Como já descrito, o fato de a habitação constituir um dos principais componentes da riqueza das famílias (73,3\% das famílias brasileiras possuem domicílio próprio), as alterações nos preços da habitação apresentam impacto significativo sobre a percepção das famílias em relação à sua riqueza e rendimento permanente, bem como sobre as suas possibilidades de endividamento. 
Gráfico 6 - Oferta e demanda por habitações da economia brasileira

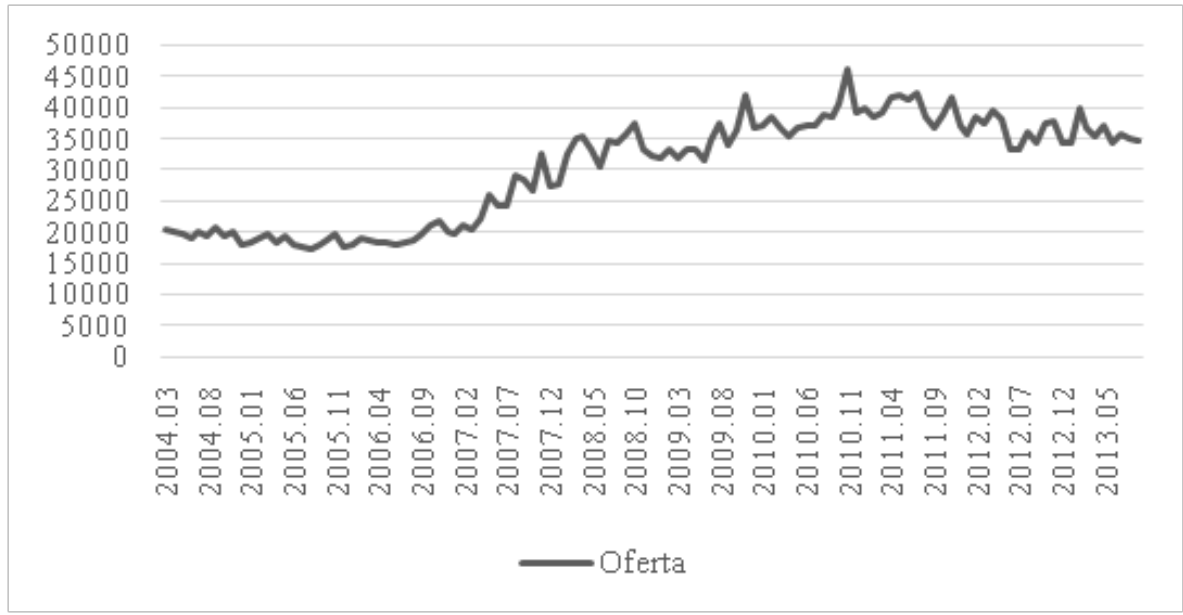

Fonte: Elaboração própria.

Nota: (*) As curvas de oferta e demanda foram obtidas a partir da soma das ofertas e demandas individuais das seguintes capitais: Belo Horizonte, Fortaleza, Goiânia, Maceió, Porto Alegre, Recife, Rio de Janeiro e São Paulo.

Outra característica do mercado habitacional brasileiro que vem sendo observada e que merece destaque é o fato de o aumento nos preços de venda das habitações ter tido efeitos expressivos na oferta de habitações, como pode ser visto no Gráfico 6.

Como descrito no relatório da Câmara Brasileira da Indústria da Construção (2010, p. 5),

[...] em 2003, apenas 19,5\% dos trabalhadores da construção possuíam vínculo formal de emprego, com registro em carteira de trabalho - em 2009; esse indicador chegou a 30,1\%. Nesse período, o contingente de trabalhadores com carteira assinada dobrou, saltando da faixa de 1 milhão de trabalhadores para 2 milhões de trabalhadores.

Com isso, o aumento nos preços das habitações tem afetado positivamente a oferta de habitações e, em virtude disso, tem aumentado a demanda por mão de obra para a construção civil, como pode ser observado no Gráfico 5. Esse choque trouxe efeitos persistentes sobre o número de horas trabalhadas na área de construção civil.

Direcionando a análise para a discussão dos efeitos desse choque sobre as variáveis de interesse, percebe-se inicialmente que o aumento nos preços das ha- 
bitações afetou positivamente o consumo das famílias e o PIB, e, em consequência desses efeitos, houve uma elevação da taxa de inflação. Os efeitos desse choque sobre a inflação brasileira ficaram próximos dos resultados encontrados por Iacoviello (2005), e, em resposta ao aumento da inflação, a taxa de juros aumentou durante todo o período analisado, sendo que o valor máximo da resposta foi alcançado no mês contemporâneo ao choque.

A resposta dada pelo Banco Central ao aumento dos preços das habitações está em conformidade com a discussão proposta por Cecchetti et al. (2000). Estes argumentam que os desalinhamentos dos preços dos ativos devem ser sistematicamente considerados pelo Banco Central em suas previsões da inflação e do hiato do produto, apesar de não ser o objetivo principal no contexto de um regime de metas de inflação. A principal razão é que bolhas nesses preços provocam distorções nos níveis de consumo e investimento e, portanto, na demanda e oferta agregadas. Uma pequena elevação (redução) nas taxas de juros quando os preços dos ativos ultrapassam (ou ficam abaixo) os níveis fundamentais compensa o impacto de uma bolha nos níveis de produção e inflação.

A conclusão obtida desta análise é que o Banco Central, buscando estabilizar a inflação e o produto, tem levado em consideração os possíveis efeitos desestabilizadores causados pelas bolhas nos preços das habitações, tentando eliminar a instabilidade financeira e a contração no produto, causadas quando estouram.

\section{Considerações Finais}

Em linhas gerais, as conclusões obtidas neste estudo mostraram que a economia brasileira apresenta indícios de bolhas racionais. Essa conclusão foi obtida por meio dos testes de cointegração linear e com quebra estrutural. Esse resultado também é descrito nos trabalhos de Besarria, Paes e Silva (2014) e Mendonça e Sachsida (2012). Apesar de utilizarem metodologias e discussões teóricas distintas, esses autores também sugerem que há indícios de bolhas nos preços desse ativo.

Em relação à discussão que analisou as respostas da política monetária e fiscal aos choques nos preços das habitações, verificou-se que a apreciação dos ativos (bolha) afetou positivamente o PIB real, o consumo das famílias e a inflação, sendo que a resposta dada pelo Banco Central a esse choque foi o aumento na taxa de juros de forma mais persistente que os efeitos desse choque sobre o PIB e a inflação.

Já a resposta fiscal a esse choque foi de aumento permanente nas receitas e nos gastos do governo, mostrando que a apreciação dos ativos imobiliários tem estimulado a atividade fiscal, trazendo um comportamento pró-cíclico para esses instrumentos de política fiscal. 


\section{Referências}

ADRIAN, T.; SHIN, H. S. Financial intermediaries, financial stability, and monetary policy. New York: Federal Reserve Bank of New York, 2008. (Working Paper, n. 346).

BANK FOR INTERNATIONAL SETTLEMENTS. Statistical data. Disponível em: <www.bis. org/statistics>. Acesso em: 20 jan. 2015.

BERNANKE, B.; GERTLER, M. Monetary policy and asset volatility. Economic Review, v. 84, n. 4, p. 17-52, 1999.

BERNANKE, B.; GERTLER, M. Should central banks respond to movements in asset prices? The American Economic Review, v. 91, n. 2, p. 253-257, 2001.

BESARRIA, C. N. Bolhas de ativos e os seus efeitos macroeconômicos. 2014. Tese (Doutorado em Economia)- Universidade Federal de Pernambuco, Pernambuco, 2014.

BESARRIA, C. N.; PAES, N. L.; SILVA, M. E. A. Como o banco central tem reagido aos choques (bolhas) nos preços das habitações brasileiras? Uma análise por meio do modelo dinâmico estocástico de equilíbrio geral (DSGE). In: ENCONTRO BRASILEIRO DE FINANÇAS, 14., 2014, Recife. Anais... Recife: Sociedade Brasileira de Finanças, 2014. Não paginado.

BIERENS, H. J. Nonparametric cointegration analysis. Journal of Econometrics, v. 77, n. 2, p. 379-404, 1997a.

. Testing the unit root with drift hypothesis against nonlinear trend stationarity, with an application to the us price level and interest rate. Journal of Econometrics, v. 81, n. 1, p. 29-64, 1997b.

BLANCHARD, O.; DELL'ARICCIA, G.; MAURO, P. Rethinking macroeconomic policy. Washington, DC: International Monetary Fund, 2010.

BOHL, M. T. Periodically collapsing bubbles in the US stock market? International Review of Economics and Finance, v. 12, n. 3, p. 385-397, 2003.

BOONE, L.; GIROUARD, N. Capital Regulation, risk-taking: a missing link in the transmission mechanism? Basel: Bank for International Settlements, 2008. (Working Paper, n. 268).

. The stock market, the housing market and consumer behaviour. Economic Studies, v. 35, n. 2, p. 175-200, 2002.

BUENO, R. L. S. Econometria de séries temporais. São Paulo: Cengage Learning, 2011.

BYRNE, J. P.; DAVIS, E. P. Disaggregate wealth and aggregate consumption: an investigation of empirical relationships for the G7. Oxford Bulletin of Economics and Statistics, v. 65, n. 2, p. 197-220, 2003.

CÂMARA BRASILEIRA DA INDÚSTRIA DA CONSTRUÇÃO. Fundação Getúlio Vargas Projetos. Uma construção cada vez mais formalizada. Brasília, DF: CBIC, 2010. p. 5.

CAMPBELL, J. Y.; SHILLER, R. J. The dividend-price ratio and expectations of future dividends and discount factors. Review of Financial Studies, v. 1, n. 3, p. 195-228, 1988. 
CANOVA, F.; NICOLÓ, G. Monetary disturbances matter for business fluctuations in the G-7. Journal of Monetary Economics, n. 49, p. 1131-1159, 2002.

CASE, K.; QUIGLEY, J.; SHILLER, R. Comparing wealth effects: the stock market versus the housing market. Advances in Macroeconomics, v. 5, n. 1, p. 1-34, 2005.

CATTE, P. et al. Housing markets, wealth and the business cycle. Paris: Organisation for Economic Co-operation and Development, Dec. 2004. (Working Paper, n. 394).

CECCHETTI, S. G. et al. Asset prices and central bank policy. Geneva: International Center for Monetary and Banking Studies; London: Centre for Economic Policy Research, 2000. (Geneva Reports on the World Economy, 2).

CHANG, T.; CHIU, C. C.; NIEH, C. C. Rational bubbles in the US stock market? further evidence from a nonparametric cointegration test. Applied Economics Letters, n. 14, p. 517$521,2007$.

CROWDER, W. J.; WOHAR, M. E. Stock price effects of permanent and transitory shocks. Economic Inquiry, v. 36, p. 540-552, 1998.

CUNADO, J.; GIL-ALANA, A. L.; GRACIA, F. P. A test for rational bubbles in the NASDAQ stock index: a fractionally integrated approach. Journal of Banking and Finance, v. 29, n. 10, p. 2633-2654, 2005.

DECRESSIN, J.; LAXTON, D. Gauging risks for deflation. Washington, D.C.: International Monetary Fund, Jan. 2009. (IMF Staff Position Note 09/01).

DIBA, B. T.; GROSSMAN, H. I. Explosive rational bubbles in stock prices? American Economic Review, v. 78, p. 520-530, 1988.

DICKEY, D. A.; FULLER, W. A. Likelihood ratio statistics for autoregressive time series with a unit root. Econometrica, v. 49, n. 4, p. 1057-1072, 1981.

ENGLE, R. F.; GRANGER, C. W. J. Co-integration and error correction: representation, estimation, and testing. Econometrica, v. 55, n. 2, p. 251-276, 1987.

EVANS, G. Pitfalls in testing for explosive bubbles in asset prices. American Economic Review, v. 81, n. 4, p. 922-930, 1991.

FAUST, J. The robustness of identified VAR conclusions about money. Washington, D.C: Board of Governors of the Federal Reserve System, Apr. 1998. (FRB International Finance Discussion Papers, n. 610).

FILARDO, A. J. Should monetary policy respond to asset price bubbles? Some experimental results. In: KAUFMAN, G. (Ed.). Asset Price Bubbles: implications for monetary and regulatory policies. Amsterdam: Elsevier Science, 2001.

FROOT, K.; OBSTFELD, M. Intrinsic bubbles: the case of stock prices. American Economic Review, v. 81, p. 1189-1214, 1991.

FUNKE, M.; PAETZ, M.; PYTLARCZYK, E. Stock market wealth effects in an estimated DSGE model for Hong Kong. Economic Modelling, v. 28, n. 1, p. 316-334, 2011. 
GILLES, C.; LEROY, S. F. Bubbles and charges. International Economic Review, v. 33, n. 2, p. 323-339, 1992.

GRANT, C.; PELTONEN, T. Housing and equity wealth effects of Italian households. Amsterdam: De Nederlandsche Bank, 2005. (Working Paper, n. 43).

GREGORY, A. W.; HANSEN, B. E. Residual-based tests for cointegration in models with regime shifts. Journal of Econometrics, v. 70, n. 1, p. 99-126, 1996.

HIMMELBERG, C.; MAYER, C.; SINAI, T. Assessing high house prices: bubbles, fundamentals and misperceptions. Journal of Economic Perspectives, v. 19, n. 4, p. 67-92, 2005.

IACOVIELLO, M. House prices and the macroeconomy in Europe: results from a structural VAR analysis. Germany: European Central Bank, Apr. 2000. (Working Paper, n. 18).

House prices, borrowing constraints, and monetary policy in the business cycle. American Economic Review, v. 95, n. 3, p. 739-764, 2005.

IBGE. Censo demográfico 2010. Disponível em: < http:/www.ibge.gov.br/home/estatistica/ populacao/censo2010/> . Acesso em: 20 jan. 2014.

INTERNATIONAL MONETARY FUND. Fiscal Monitor: Balancing Fiscal Policy Risks. Washington, D.C.: IMF, Apr. 2012.

JOHANSEN, S.; JUSELIUS, K. Maximum likelihood estimation and inference on cointegration: with applications to the demand for money. Oxford Bulletin of Economics and Statistics, v. 52, n. 2, p. 169-210, 1990.

KIVEDAL, B. K. Testing for rational bubbles in the US housing market. Journal of Macroeconomics, v. 38, p. 369-381, 2013.

LEISTER, M. D. Bolhas e política monetária: evidências para a economia brasileira. 2011. 199 f. Tese (Doutorado em Economia) - Universidade de São Paulo, São Paulo, 2011.

LUDWIG, A.; SLØK, T. The relationship between stock prices, house prices and consumption in OECD countries. Topics in Macroeconomics, v. 4, n. 1, p. 1- 28, 2004.

MACKINNON, J. G.; HAUG, A. A.; MICHELIS, L. Numerical distribution functions of likelihood ratio tests for cointegration. Journal of Applied Econometrics, v. 14, n. 5, p. 563-577, 1999.

MEIRELLES, H. Henrique Meirelles: entrevista [nov. 2013]. Entrevistadora: Paula Pacheco. São Paulo: Portal iG, 2013. Entrevista concedida ao iG.

MENDONÇA, M. J.; MEDRANO, L. A.; SACHSIDA, A. Avaliando o efeito de um choque de política monetária sobre o mercado imobiliário. Brasília, DF: Ipea, 2011. (Texto para Discussão, n. 1631).

MENDONÇA, M. J.; SACHSIDA, A. Existe bolha no mercado imobiliário brasileiro? Brasília, DF: Ipea, 2012. Disponível em: <http:/www.ipea.gov.br/portal/index.php?option=com contentEview $=$ articleEjid $=15348 \geq$. Acesso em: 02 fev. 2013. 
MERROUCHE, O.; NIER, E. What caused the global financial crisis? Evidence on the drivers of financial imbalances 1999-2007. Washington, D.C.: International Monetary Fund, 2010. (Working Paper, n. 265).

MIAO, J.; WANG, P.; XU, Z. A Bayesian DSGE model of stock market bubbles and business cycles. Stonybrook, NY: Economic Dynamics Marina Azzimonti, Department of Economics Stonybrook University, 2013. (Meeting Papers, n. 167).

MISHKIN, F. S. Housing and the monetary transmission mechanism. Cambridge, MA: National Bureau of Economic Research, 2007. (Working Paper, n. 13518).

MOKHTAR, S. H.; NASSIR, A. M.; HASSAN, T. Detecting rational speculative bubbles in the Malaysian stock market. International Research Journal of Finance and Economics, v. 6, p. 102-115, 2006.

MORETTIN, P. A. Econometria financeira: um curso em séries temporais. São Paulo: Blucher, 2008.

MUELLBAUER, J. The assessment: consumer expenditure. Oxford Review of Economic Policy, v. 10, n. 2, p. 1-41, 1994.

NASSEH, A.; STRAUSS, J. Stock prices and the dividend discount model: did their relation break down in the 1990s. The Quarterly Review of Economics and Finance, v. 44, n. 2, p. 191207, 2004.

NORMAN, B.; BARRIEL, M.; WEEKEN, O. Equity wealth and consumption-the experience of Germany, France and Italy in an international context. London: Bank of England, Spring, 2002. (Bank of England Quarterly Bulletin).

NUNES, M. S.; SILVA, S. Bolhas racionais no Índice Bovespa. Revista Brasileira de Economia, Rio de Janeiro, v. 63, n. 2, p. 119-134, 2009.

PACHECO, L. M. M. A. D.; BARATA, J. M. O mecanismo de transmissão da política monetária: o papel dos preços dos activos. 2006. 403 f. Tese (Doutorado em Economia) - Instituto Superior de Economia e Gestão, Universidade Técnica de Lisboa, Lisboa, 2006. Disponível em: < https://www.repository.utl.pt/handle/10400.5/735>. Acesso em: 10 nov. 2014.

PAES, N. L. Curso de economia do setor público III. Recife: Programa de Pós-Graduação em Economia da Universidade Federal de Pernambuco, 2012.

PAIELLA, M. Does wealth affect consumption? Evidence for Italy. Roma: Banca d“Italia, jul. 2004. (Temi di discussione, n. 510).

RATTO, M.; ROEGE, W.; VELD J. Using a DSGE model to look at the recent boom-bust cycle in the US. Belgium: Economic and Financial Affairs; European Commission, 2010. (Working Paper, n. 397).

SECOVI-SP: O SINDICATO DA HABITAÇÃO. Pesquisas e índices. Disponível em: <www. secovi.com.br>.Acesso em: 20 jan. 2015. 
SECRETARIA DA RECEITA FEDERAL DO BRASIL. Dados econômico-tributários e aduaneiros da Receita Federal. Disponível em: <idg.receita.fazenda.gov.br/dados>. Acesso em: 20 fev. 2015.

SHILLER, R. J. Robert J. Shiller: entrevista [2013]. Entrevistadora: Julia Wiltgen. São Paulo: Exame, out. 2013. Entrevista concedida ao site EXAME.com.

SILVA, M. E.; BESARRIA, C. N.; CARVALHO, D. B. Efeitos dos choques fiscais e monetários sobre o mercado imobiliário Brasileiro. In: ENCONTRO BRASILEIRO DE ECONOMETRIA, 36., 2014, Natal. Anais... Natal: Conselho Regional de Economia, 2014. p. 1-28.

SILVER, N. O sinal e o ruído. Rio de Janeiro: Intrinseca, 2013.

TAYLOR, J. B. Housing and monetary policy. Kansas: Federal Reserve Bank of Kansas City, 2007. (Working Paper, n. 13682).

TIMMERMANN, A. Cointegration tests of present value models with a time-varying discount factor. Journal of Applied Econometrics, v. 10, n. 1, p. 17-31, 1995.

UHLIG, H., What are the effects of monetary policy on output? Results from an agnostic identification procedure. Journal of Monetary Economics, v. 52, n. 2, p. 381-419, 2005.

WANG, P.; WEN, Y. Speculative bubbles and financial crises. American Economic Journal, v. 4, n. 3, p. 184-221, 2012.

WOODFORD, M. Methods of policy accommodation at the interest-rate lower bound, presented at the changing policy landscape. In: FRB KANSAS CITY ECONOMIC POLICY SYMPOSIUM, 2012, Jackson. Anais... Jackson: Federal Reserve Bank of Kansas City, 2012. p. 185-288.

WU, Y. Rational bubbles in the stock market: accounting for the U.S. stock-price volatility. Economic Inquiry, v. 35, n. 2, p. 309-319, Apr. 1997.

Recebido em: 10/02/2015. Aceito em: 11/05/2016. 